\title{
Endoscopic thoracic sympathectomy
}

\section{J. Patrick Johnson, M.D., Chinyere Obasi, M.B.B.S., F.R.C.S.C., Michael S. Hahn, M.D., and Paul Glatleider, M.D.}

Division of Neurosurgery, University of California, Los Angeles; and Kaiser Permanente Medical Center, Los Angeles, California

Thoracic sympathectomy has evolved as a treatment option for patients with hyperhidrosis and pain disorders. In the past surgical procedures were highly invasive and caused significant morbidity, but the minimally invasive thoracoscopic procedure provides detailed visualization of the sympathetic ganglia and is associated with minimal postoperative morbidity. In a previously published series the authors performed 60 thorascopic procedures in 39 patients; in this paper, they report the addition of 52 procedures performed in 26 patients, for a total of 112 procedures in 65 patients. Overall, the outcomes were equivalent to those for previously established open surgical techniques; however, the rate of surgery-related morbidity, length of hospital stay, and time until return to normal activity were substantially reduced. Complications and recurrence of symptoms were comparable with those demonstrated in previous reports. Overall patient satisfaction and willingness to undergo a repeat operative procedure ranged from 66 to $99 \%$. Postoperatively, higher satisfaction rates were observed in patients with hyperhidrosis whereas in those with pain syndromes, satisfaction rates were lower. Minimally invasive thoracoscopic sympathectomy procedures are useful in treating sympathetically mediated disorders, and the results indicated that the procedure is associated with reduced morbidity and similar outcome when compared with results obtained after open surgery. Hyperhidrosis is well treated, but patients with pain syndromes have significantly poorer outcomes.

\section{Key Words * thoracoscopy * sympathectomy * hyperhidrosis * Raynaud's syndrome * causalgia}

In the past decade[3,7,10,22-26] video-assisted endoscopic imaging has made minimally invasive procedures technically feasible. Treatment of sympathetically mediated syndromes affecting the upper extremities, including hyperhidrosis, pain syndromes (causalgia or reflex sympathetic dystrophy, now commonly referred to as complex regional pain syndrome [CRPS]), and Raynaud's syndrome, are the primary indications for thoracoscopic sympathectomy.[1,3,7,10,11,21,24] Thoracoscopy provides a magnified view of the sympathetic chain and adjacent anatomy for precise surgical resection of the sympathetic ganglia, and it avoids the morbidity associated with open thoracotomy, supraclavicular, and paraspinal procedures.[10,22] Because length of hospital stay (LOS) and morbidity rates are reduced, patient satisfaction is improved, which now makes thoracoscopic sympathectomy the preferred procedure 
for these disorders; however, long-term outcome studies have been limited.

\section{CLINICAL MATERIALS AND METHODS}

\section{Patient Population}

In a previously published paper,[15] we reported on the outcome of 39 patients who underwent 60 thorascopic procedures for sympathetically mediated pain disorders between 1993 and 1995. In this report, we update the series, providing outcome data for an additional 26 patients who underwent 52 procedures between 1996 and 1999. The reuslts presented here represent a combination of both time periods. All procedures were performed to treat uni- or bilateral symptoms. Overall, 20 patients underwent a unilateral thoracoscopic sympathectomy procedure, whereas 11 patients with bilateral symptoms underwent staged thoracoscopic procedures several weeks apart in the early phase of the series (1993-1995). During the most recent 4-year period, 34 patients with bilateral symptoms have undergone sequentially staged same-day thoracoscopic procedures.

\section{Indications and General Considerations}

Patients with sympathetically mediated syndromes, such as hyperhidrosis, CPRS, causalgia, and Raynaud's syndrome, and those in whom medical treatment failed to relieve pain underwent sympathectomy. Imaging studies such as chest radiography and computerized tomography or magnetic resonance imaging of the cervical and thoracic spine and brachial plexus were necessarily performed in each case. Psychological evaluation, an important component in the evaluation of patients with chronic pain, was performed as well. Stellate ganglion anesthetic blocks were used to obtain diagnostic confirmation that symptoms would be responsive to sympathetic blockade in patients with pain and ischemic disorders and only in a limited number of patients with hyperhidrosis regarding diagnostic blocks.

\section{Intubation and Positioning}

General anesthesia was induced, and patients underwent selective intubation, with single-lung ventilation being required for patients in whom a thoracoscopic sympathectomy was to be performed. Positioning of the patient during the procedure has evolved during the present series (Table 1).

\begin{tabular}{|c|c|c|}
\hline \multicolumn{3}{|c|}{$\begin{array}{c}\text { TABLE } 1 \\
\text { SVMPATHECTOMN PROCEDURES IN WH ICH UNI-AND } \\
\text { BILATERAL APPROACHES WERE USED IN } 65 \text { PATIENTS } \\
\text { WHO UNDERWENT } 112 \text { PROCEDURES } \\
\end{array}$} \\
\hline Approach & $\begin{array}{l}\text { No. of } \\
\text { Patients }\end{array}$ & $\begin{array}{c}\text { No. of } \\
\text { Procedures }\end{array}$ \\
\hline $\begin{array}{l}\text { unilat } \\
\text { bilat (stage }\end{array}$ & $\begin{array}{l}20 \\
11\end{array}$ & $\begin{array}{l}22 \\
22\end{array}$ \\
\hline tilat (same & 34 & \\
\hline
\end{tabular}

Early in the series, patients underwent surgery while in a lateral position with the side in which surgery was performed facing up (Fig.1), and in patients with bilateral symptoms surgery was performed on the opposite side several weeks later. Later in the series, those patients with bilateral symptoms who were undergoing bilateral sympathectomies were repositioned for an immediate second-stage procedure on the contralateral side. Currently, in patients requiring bilateral sympathectomies the procedure is performed 
while the patient is in the supine position to obtain exposure of both axillary regions in immediately staged procedures (Fig. 2).

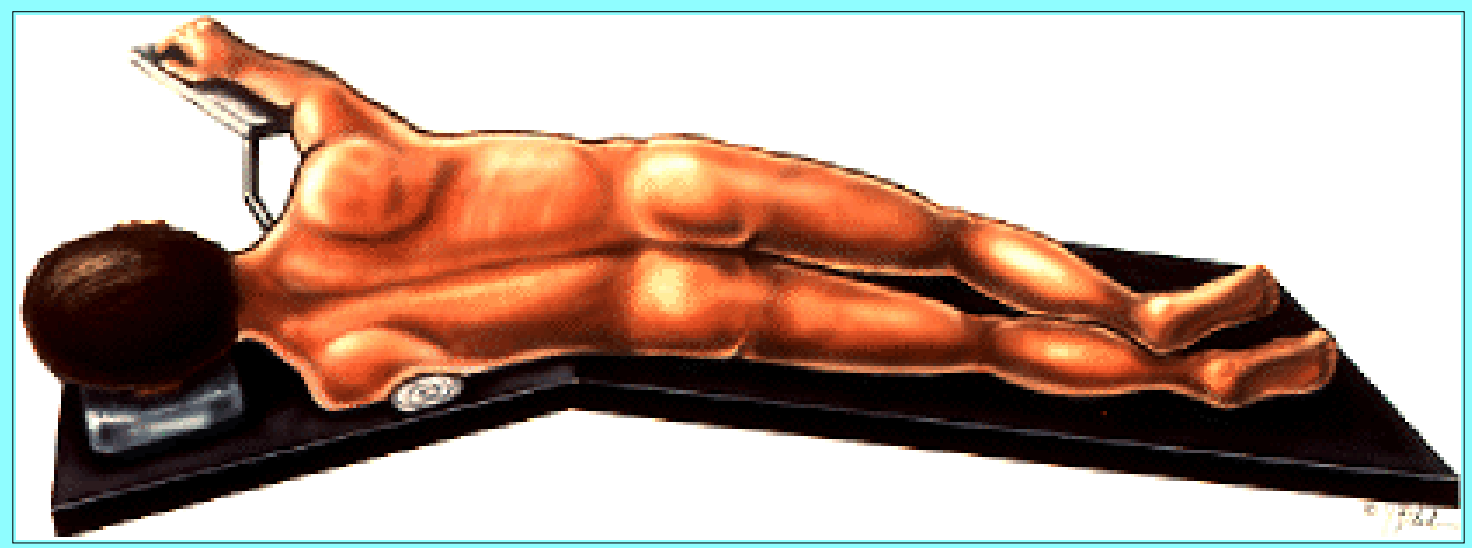

Fig. 1. Artist's drawing depicting the lateral positioning of the patient (same as for a thoracotomy) undergoing right thoracoscopic sympathectomy.

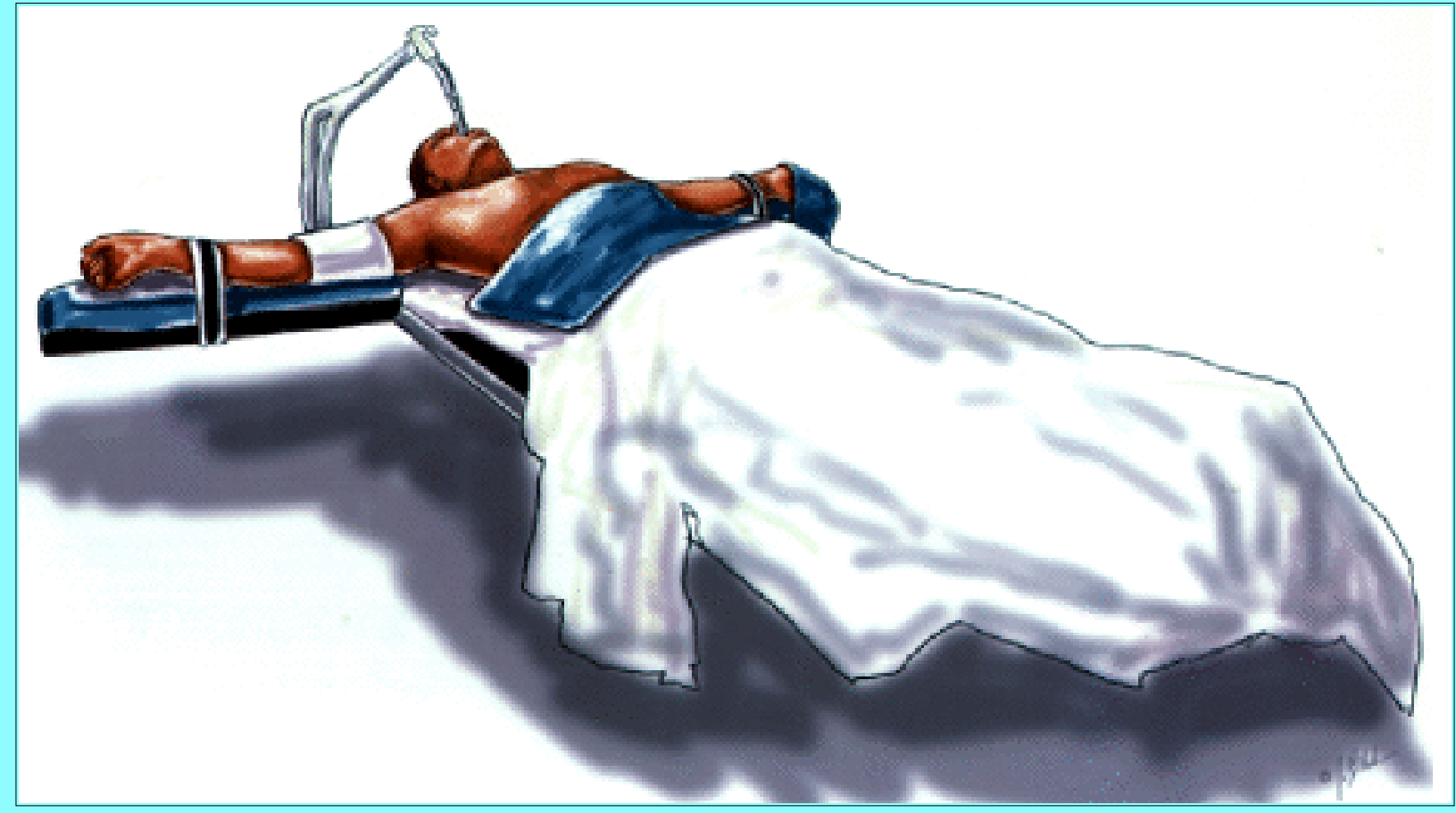

Fig. 2. Artist's drawing illustrating the supine positioning of the patient undergoing sequential bilateral thoracoscopic sympathectomies.

To view the following sections previously described in Neurosurgical Focus 4 (2): Article 4, 1998, click the heading below. Please note that reference numbers in these two manuscripts do not correspond.

\section{Equipment and Instruments[14]}

\section{Ports and Placement[14]}

Steps of the Procedure [14]

Postoperative Care[14] 
The follow-up period was 6 months to 6 years, with annual clinic evaluations of all patients after thoracoscopic sympathectomy. Further details are described in the earlier work.[14]

\section{RESULTS}

The largest group of patients were those with hyperhidrosis (Table 2) who underwent thoracoscopic sympathectomy, and they also had the highest success rates (Tables 3 and 4).

\begin{tabular}{|lc|}
\hline \multicolumn{2}{|c|}{ TABLE 2 } \\
\multicolumn{2}{|c|}{ DIAGNOSIS IN PATIENTS UNDERGONG } \\
THORACOSCOPIC SVMPATHECTOMN
\end{tabular}

\begin{tabular}{|c|c|c|c|c|}
\hline \multicolumn{5}{|c|}{$\begin{array}{c}\text { TABLE } 3 \\
\text { OUTCOME IN } 48 \text { PATIENTS WITH HY PERH DROSS }\end{array}$} \\
\hline Symptom & $\begin{array}{c}\text { Relief of } \\
\text { Symptorns }\end{array}$ & $\begin{array}{l}\text { Parbial Reli ef } \\
\text { of Symptoms }\end{array}$ & $\begin{array}{l}\text { Recurrent } \\
\text { Symptoms }\end{array}$ & $\begin{array}{c}\text { Loot to } \\
\text { Follow }\end{array}$ \\
\hline hyperhidrosis & 47 & 1 & 0 & 0 \\
\hline
\end{tabular}

\begin{tabular}{|lcc|}
\hline \multicolumn{3}{|c|}{ TABLE 4 } \\
PATENT SAT SFACTION AND WILLINGNESS TO \\
UNDERGO RE PEATED PROCEDURE*
\end{tabular}

Also in this group the highest complication rates were demonstrated, most often related to compensatory hyperhidrosis (manifesting as sweating in the trunk/torso or gustatory sweating); however, most patients were sufficiently satisfied with the postoperative result. Patients treated for pain syndromes or vasculitic disorders are noted in Table 2, and their initial response to treatment was very high; however, the effectiveness of treatment diminished after more than 6 months postoperatively (Tables 4-6), and the recurrence of symptoms was variable in these patients. Symptoms did not worsen in any patient who underwent sympathecotmy, and the causes of symptom recurrence are unknown. Their overall satisfaction and willingness to repeat the operative treatment was correspondingly decreased (Table 4). 
TABLE 5

OUTCOMES IN 17 PATIENTS WITH PAIN AND YASCULITIS DISORDERS

\begin{tabular}{lccc|}
\hline \hline & \multicolumn{3}{c|}{ No. of Patierts } \\
\cline { 2 - 4 } \multicolumn{1}{c}{ Disorder } & $\begin{array}{c}\text { Relief of } \\
\text { Symptorns }\end{array}$ & $\begin{array}{c}\text { Recurrence } \\
\text { of Symptons }\end{array}$ & $\begin{array}{c}\text { Lost to } \\
\text { Follow Up }\end{array}$ \\
\hline $\begin{array}{l}\text { RSD causadgia/CRPS } \\
\begin{array}{c}\text { (12 patients) } \\
\text { Raynaud's syndrome Nasculitis } \\
\text { (5 patients) }\end{array}\end{array}$ & 7 & 4 & 1 \\
\hline
\end{tabular}

\begin{tabular}{|c|c|c|c|}
\hline \multicolumn{4}{|c|}{$\begin{array}{c}\text { TABLE } 6 \\
\text { OUTCOMES IN PATIENTS WITH PAIN AND YASCULITIS DISORDERS AS } \\
\text { MEASURED BV THE OSWESTRY PAIN SCALE* }\end{array}$} \\
\hline \multirow[b]{2}{*}{ Disorder } & \multicolumn{3}{|c|}{ Owesby Pain Scale Score } \\
\hline & $\begin{array}{l}\text { Preop } \\
{[\%]}\end{array}$ & $\begin{array}{c}1+m 0 \\
\text { Postop }[\%]\end{array}$ & $\begin{array}{l}>6+m 03 \\
P \cos t a p(\%)\end{array}$ \\
\hline $\begin{array}{l}\text { RSD tausalgia/CRPS } \\
\text { Raynaud's syndrome hasculits }\end{array}$ & $\begin{array}{l}42 \\
51\end{array}$ & $\begin{array}{l}92 \\
96\end{array}$ & $\begin{array}{l}65 \\
88\end{array}$ \\
\hline
\end{tabular}

Hospital LOS was short in those patients who underwent thoracoscopic sympathectomy: most patients remained 1 or 2 days postoperatively (Table 7). In historical cohorts of patients at our institution who underwent posterior paraspinal sympathectomies, hospital LOS ranged from 3 to 6 days. The overall complication rates (Table 8 ) were comparable with previous treatment alternatives.

\begin{tabular}{|lcc|}
\hline \multicolumn{3}{|c|}{$\begin{array}{c}\text { TABLE 7 } \\
\text { HOSPITAL LOS FOLLOWING THORACOSCOPIC } \\
\text { SVMPATHECTOM }\end{array}$} \\
\hline \hline Duration & $\begin{array}{c}\text { Unilat Sympa- } \\
\text { thectomy [days) }\end{array}$ & $\begin{array}{c}\text { Bilat Sympa- } \\
\text { thectomy (day) }\end{array}$ \\
\hline median & 1 & 2 \\
mean & 1.5 & 1.8 \\
range & $0-4$ & $1-3$ \\
\hline \multicolumn{4}{|c}{} \\
\hline
\end{tabular}




\begin{tabular}{|c|c|}
\hline $\begin{array}{c}\text { TABLE } 8 \\
\text { POSTOPERATIVE COMPLKATONS AFTE }\end{array}$ & MPATHECTOMN \\
\hline Complicalions & No. of Patierts \\
\hline Horner's Syndrome & \\
\hline transient & 7 \\
\hline permanent & 1 \\
\hline com pensator yh yperhidrosis & 11 \\
\hline gustatory sweating & 2 \\
\hline pheum othorax (requiring chest tube) & 1 \\
\hline $\begin{array}{l}\text { pleural e fusion (not requiring thora- } \\
\text { cocente sis or chest tube) }\end{array}$ & 4 \\
\hline mound infection & 1 \\
\hline in tercostal neuralgia & \\
\hline transient & 3 \\
\hline permanent & 1 \\
\hline death† & 1 \\
\hline $\begin{array}{l}\text { "Patients with hyperhidrosis who or } \\
\text { pensatory sweating sym ptoms. } \\
\dagger \text { Death ocourred in an elderly pa } \\
\text { Raynaud's syndrome who suffered a } \\
1 \text { month after undergoing an uncom pli } \\
\text { pathectom y' procedure. }\end{array}$ & $\begin{array}{l}\text { perienced com- } \\
\text { with intractable } \\
\text { ardial infarction } \\
\text { unilateral sym- }\end{array}$ \\
\hline
\end{tabular}

\section{DISCUSSION}

\section{Evolution of Sympathectomy Techniques}

By utilizing recently evolved techniques for thoracic sympathectomy we can now achieve improved patient care and outcomes. $[3,6,14,15,17,18]$ Previously, sympathetically mediated syndromes required highly invasive surgical procedures to resect a relatively small portion of the upper thoracic sympathetic ganglia.[2,4,5,9,13,28,30,31] Despite these issues, previous surgical procedures produced acceptable long-term clinical results.[2,4,5,9,26,31] Open operative procedures to treat hyperhidrosis have successfully resolved symptoms in more than $95 \%$ of cases, and in patients with pain disorders long-term improvement has been only 60 to $80 \%$ of cases.[5,22,28,31] Consequently, less traumatic and invasive procedures for sympathectomy have been sought.

\section{History of Thoracoscopy Procedures}

For a summary of the uses of thoracoscopic procedures[14], click on the heading.

\section{Hyperhidrosis}

A thorough characterization of hyperhidrosis can be found by clicking the heading and viewing our previously published paper.[14] One finding not discussed in our earlier work was that compensatory hyperhidrosis was found to occur in $22 \%$ of patients in our series, which is consistent with that reported in other series.

\section{Pain Syndromes, Raynaud's Syndrome and Vasculitis, and Thoracoscopy-Related Complications}

For a discussion of these topics, click the heading to view the previous report.[14]

\section{CONCLUSIONS}


In the treatment of sympathetically mediated disorders, minimally invasive techniques for thoracoscopic sympathectomy have equivalent outcomes to those reported for previous open surgical techniques; however, the associated morbidity rate and the hospital LOS are substantially reduced when utilizing these newer techniques. We recommend that surgeons undergo formal training in these procedures, with didactic and laboratory training, followed by work with an experienced surgeon who performs these procedures on a regular basis.

\section{Acknowledgments}

The authors wish to thank Joe Bloch for his artistic illustrations and Samantha Phu for assistance with this manuscript.

\section{References}

1. AbuRahma AF, Robinson PA, Powell M, et al: Sympathectomy for reflex sympathetic dystrophy: factors affecting outcome. Ann Vasc Surg 8:372-379, 1994

2. Adson AW: Changes in technique of cervicothoracic ganglionectomy and trunk resection. Am J Surg 23:287-288, 1934

3. Ahn SS, Machleder HI, Concepcion B, et al: Thoracoscopic cervicodorsal sympathectomy: preliminary results. J Vasc Surg 20:511-519, 1994

4. Atkins HBJ: Sympathectomy by the axillary approach. Lancet 1:538-539, 1954

5. Cloward RB: Hyperhidrosis. J Neurosurg 30:545-551, 1969

6. Drott C: The history of cervicothoracic sympathectomy. Eur J Surg Suppl 572:5-7, 1994

7. Dumont P, Hamm A, Skrobala D, et al: Bilateral thorascopy for sympathectomy in the treatment of hyperhidrosis. Eur J Surg 11:774-775, 1997

8. Edwards JM, Porter JM: Associated diseases with Raynaud's syndrome. Vasc Med Rev 1:51-58, 1990

9. ganglion for the sympathtetic supply of the upper extremities, with a description of two new approaches for its removal in cases of vascular disease: preliminary report. Clin Proc 3:102-114, 1944

10. Hashmonai M, Kopelman D, Schein M: Thoracoscopic versus open supraclavicular upper dorsal sympathectomy: a prospective randomised trial. Eur J Surg Suppl 572:13-16, 1994

11. Herz DA, Looman JE, Ford RD, et al: Second thoracic sympathetic ganglionectomy in sympathetically maintained pain. J Pain Symptom Manage 8:483-491, 1993

12. Hughes J: Endothoracic sympathectomy. Proc R Soc Med 35:585-586, 1942

13. Jacobaeus HC: Uber die Möglichkeit die Zystoskopie bei Untersuchung seröser Höhlungen anzuwenden. Munch Med Wochenschr 40:2090-2092, 1910

14. Johnson JP, Ahn SS, Choi WC, et al: Thoracoscopic sympathectomy: techniques and outcomes. Neurosurg Focus 4 (2):Article 4, 1998

15. Johnson JP, Ahn SS, Moosy, JJ et al: Surgery of the sympathetic nervous system, in Benzel EC (ed): 
Spine Surgery: Techniques, Complication Avoidance and Management. New York: Churchill Livingstone, 1999, Vol 2, pp 933-946

16. Kao MC, Tsai JC, Lai DM, et al: Autonomic activities in hyperhidrosis patients before, during, and after endoscopic laser sympathectomy. Neurosurgery 34:262-268, 1994

17. Kux E: The endoscopic approach to the vegetative nervous system and its therapeutic possibilities. Dis Chest 20:139-147, 1951

18. Kux E: Thorakoskopiche Eingriffe am Nervensystem. Stuttgart: Thieme, 1954

19. Kux M: Thoracic endoscopic sympathectomy in palmar and axillary hyperhidrosis. Arch Surg 113:264-266, 1978

20. Lai YT, Yang LH, Chio CC, et al: Complications in patients with palmar hyperhidrosis treated with transthoracic endoscopic sympathectomy. Neurosurgery 41:110-115, 1997

21. Landry GJ, Edwards JM, Porter JM: Current management of Raynaud's syndrome. Adv Surg 30:333-347, 1997

22. Mockus MB, Rutherford RB, Rosales C, et al: Sympathectomy for causalgia. Patient selection and long-term results. Arch Surg 122:668-672, 1987

23. Nicholson ML, Dennis MJS, Hopkinson BR: Endoscopic transthoracic sympathectomy: successful in hyperhidrosis but can the indications be extended? Ann R Coll Surg Engl 76:311-314, 1994

24. Noppen M, Dendale P, Hagers Y, et al: Changes in cardiocirculatory autonomic function after thoracoscopic upper dorsal sympathicolysis for essential hyperhidrosis. J Autonom Nerv Syst 60:115-120, 1996

25. Noppen M, Herregodts P, Dendale P, et al: Cardiopulmonary exercise testing following bilateral thoracoscopic sympathicolysis in patients with essential hyperhidrosis. Thorax 50:1097-1100, 1995

26. Noppen M, Herregodts P, D'Haese J, et al: A simplified T2-T3 thoracoscopic sympathicolysis technique for the treatment of essential hyperhidrosis: short-term results in 100 patients. J Laparoendosc Surg 6:151-159, 1996

27. Noppen M, Sevens C, Gerlo E, et al: Plasma catecholamine concentrations in essential hyperhidrosis and effects of thoracoscopic D2-D3 sympathicolysis. Eur J Clin Invest 27:202-205, 1997

28. Roos DB: Transaxillary extrapleural thoracic sympathectomy, in Bergan JJ, Yao JST (eds): Operative Techniques in Vascular Surgery. New York: Grune \& Stratton, 1980, p 115

29. Samuelsson H, Claes G, Drott C: Endoscopic electrocautery of the upper thoracic sympathetic chain: a safe and simple technique for treatment of sympathetically maintained pain. Eur J Surg Suppl 572:55-57, 1994

30. Telford ED: The technique of sympathectomy. Br J Surg 23:448-450, 1935

31. White JC, Smithwick RH, Allen AW, et al: A new muscle splitting incision for resection of the upper thoracic sympathetic ganglia. Surg Gynecol Obstet 56:651-657, 1933 
32. Wilkinson HA: Percutaneous radiofrequency upper thoracic sympathectomy: a new technique. Neurosurgery 15:811-814, 1984

Manuscript received March 22, 1999.

Accepted in final form April 28, 1999.

Address reprint requests to: J. Patrick Johnson, M.D., Division of Neurosurgery, UCLA Medical Center, Box 956901, Los Angeles, CA 90095-6901. email: johnson@ surgery.medsch.ucla.edu. 